\title{
Health state utilities and quality of life in patients with hepatitis B
}

\author{
Gloria Woo $\mathrm{PhD}^{1,2}$, George Tomlinson $\mathrm{PhD}^{1,3,4}$, Colina Yim RN MN5,6, Les Lilly $\mathrm{MD}^{4}$, George Therapondos $\mathrm{MD}^{7}$, \\ David KH Wong MD ${ }^{6,8}$, Wendy Ungar $\mathrm{PhD}^{3,9}$, Thomas R Einarson PhD ${ }^{2}$, Morris Sherman MB BCh $\mathrm{PhD}^{4,8}$, \\ E Jenny Heathcote $\mathrm{MD}^{6,8}$, Murray Krahn MD MSc${ }^{1,2,4}$
}

\begin{abstract}
G Woo, G Tomlinson, C Yim, et al. Health state utilities and quality of life in patients with hepatitis B. Can J Gastroenterol 2012;26(7):445-451.
\end{abstract}

BACKGROUND:The effect of chronic hepatitis B (CHB) infection on health-related quality of life (HRQoL) and health state utilities has not been well characterized.

OBJECTIVE: To measure utility scores and HRQoL across disease states associated with $\mathrm{CHB}$ infection.

METHODS: Patients attending four tertiary care clinics for $\mathrm{CHB}$ were approached between July 2007 and March 2009. Respondents completed version 2 of the Short-Form 36 Health Survey, the EQ5D, a visual analogue scale, the Health Utilities Index Mark 3, standard gamble, and demographics and risk factor surveys in English, Cantonese or Mandarin. Charts were reviewed to determine disease stage and comorbidities.

RESULTS: A total of 433 patients were studied: 294 had no cirrhosis; 79 had compensated cirrhosis; seven had decompensated cirrhosis; 23 had hepatocellular carcinoma; and 30 had received a liver transplant. The mean standard gamble utilities for these disease states were $0.89,0.87,0.82,0.84$ and 0.86 , respectively. HRQoL scores in noncirrhotic patients were similar to those of the general population. Scores of patients with compensated cirrhosis were not significantly lower; however, patients with decompensated cirrhosis and hepatocellular carcinoma had significantly lower HRQoL scores compared with noncirrhotic patients $(\mathrm{P}<0.05)$. Similar scores were observed among patients on and off oral antiviral treatment. Post-liver transplant patients had a higher HRQoL than patients with decompensated cirrhosis. Age, number of comorbidities and relationship status were significantly associated with HRQoL scores.

CONCLUSIONS: HRQOL in CHB patients is only impaired in the later stages of liver disease. Neither CHB infection nor antiviral treatment is associated with a lower quality of life.

Key Words: Health utilities; Hepatitis B; Quality of life

ore than two billion individuals worldwide have been infected 1 with the hepatitis B virus (HBV) at some point in their lives and approximately 400 million remain chronically infected (1). Although effective vaccination strategies have been implemented as a preventive measure in Canada and the United States, as many as 1.2 million to 1.8 million individuals remain chronically infected (2-4). Chronic hepatitis $\mathrm{B}(\mathrm{CHB})$ infection has been associated with increased risk of liver failure and hepatocellular carcinoma (HCC), and is a leading cause of liver disease, liver-related death and liver morbidity globally (5).

Most chronically infected individuals are unaware of their infection because they remain asymptomatic for many years (6); consequently,

\section{L'état de santé et la qualité de vie chez les patients atteints d'hépatite $B$}

HISTORIQUE : L'effet de l'infection par l'hépatite B chronique (HBC) sur la qualité de vie liée à la santé (QdVLS) et sur l'état de santé est mal caractérisé.

OBJECTIF : Mesurer les indices de l'état de santé et de la QdVLS selon les états pathologiques associés à l'infection par l'HBC.

MÉTHODOLOGIE : Les chercheurs ont communiqué avec des patients qui fréquentaient quatre cliniques de soins tertiaires pour traiter leur HBC entre juillet 2007 et mars 2009. Les répondants ont rempli la version 2 de l'enquête courte sur la santé en 36 questions, l'EQ5D, une échelle analogique visuelle, l'indice sur l'état de santé, le pari standard et des sondages sur les renseignements démographiques et les facteurs de risque en anglais, en cantonais ou en mandarin. Ils ont analysé les dossiers pour établir la phase de la maladie et les comorbidités.

RÉSULTATS : Au total, les chercheurs ont étudié 433 patients : 294 n'avaient pas de cirrhose, 79 avaient une cirrhose compensée, sept, une cirrhose décompensée, 23 , un carcinome hépatocellulaire et 30 avaient reçu une greffe du foie. Le pari standard moyen de ces états pathologiques était de $0,89,0,87,0,82,0,84$ et 0,86, respectivement. Les indices de QdVLS chez les parents non cirrhotiques étaient similaires à ceux de la population générale. Les indices des patients ayant une cirrhose compensée n'étaient pas significativement plus faibles, mais les patients ayant une cirrhose décompensée ou un carcinome hépatocellulaire présentaient un indice de QdVLS considérablement moins élevé que les patients non cirrhotiques $(\mathrm{P}<0,05)$. On observait des indices similaires chez les patients qui prenaient une antivirothérapie et ceux qui n'en prenaient pas. Les patients qui avaient subi une greffe du foie présentaient une QdVLS plus élevée que les patients ayant une cirrhose décompensée. Lâge, le nombre de comorbidités et l'état civil s'associaient de manière significative aux indices de QdVLS.

CONCLUSIONS : La QdVLS chez les patients atteints d'une HBC ne se détériore que dans les dernières phases de la maladie hépatique. $\mathrm{Ni}$ l'infection par l'HBV ni l'antivirothérapie ne s'associent à une diminution de la qualité de vie.

it has often been assumed that infection with HBV without advanced liver disease does not result in impaired health-related quality of life (HRQoL). There have been many studies of HRQoL conducted in patients with chronic hepatitis $\mathrm{C}(\mathrm{CHC})$ infection that have reported impaired HRQOL independent of the severity of liver disease. Evidence describing the impact of HBV infection on quality of life is limited. The utilities of individuals chronically infected with hepatitis $\mathrm{C}$ have frequently been used in decision and cost-effectiveness models evaluating the treatment of patients with $\mathrm{CHB}(7,8)$.

Since 2007, several studies have reported on HRQoL in patients with CHB (9-11) with varying results. In some studies, patients with $\mathrm{CHB}$ and uninfected controls were asked to evaluate descriptions of

\footnotetext{
${ }^{1}$ Toronto Health Economics and Technology Assessment Collaborative (THETA); ${ }^{2}$ Leslie Dan Faculty of Pharmacy, University of Toronto; ${ }^{3}$ Institute of

Health Policy, Management and Evaluation, University of Toronto; ${ }^{4}$ Toronto General Research Institute and Clinical Studies Resource Centre,

University Health Network; ${ }^{5}$ Department of Nursing, University of Toronto; ${ }^{6}$ Toronto Western Research Institute, University Health Network,

Toronto, Ontario; ${ }^{7}$ Multiorgan Transplant Institute, Oschner Clinic Foundation, New Orleans, Louisiana, USA; ${ }^{8}$ Department of Medicine, University

of Toronto; ${ }^{9}$ Child Health Evaluative Sciences, The Hospital for Sick Children, Toronto, Ontario

Correspondence: Dr Gloria Woo, Department of Pharmaceutical Sciences, Suite 658, 144 College Street, University of Toronto, Toronto, Ontario M5S 3M2.

Telephone 416-946-3718, fax 416-946-3719, e-mail gloria.woo@theta.utoronto.ca

Received for publication November 13, 2011. Accepted November 25, 2011
} 
TABLE 1

Sociodemographic and clinical characteristics comparison of hepatitis B respondents at different disease stages

\begin{tabular}{|c|c|c|c|c|c|}
\hline & \multirow{2}{*}{$\begin{array}{c}\text { Noncirrhotic chronic } \\
\text { hepatitis B } \\
(n=294)\end{array}$} & \multicolumn{2}{|c|}{ Cirrhosis } & \multirow[b]{2}{*}{$\begin{array}{c}\text { Hepatocellular } \\
\text { carcinoma }(n=23)\end{array}$} & \multirow[b]{2}{*}{$\begin{array}{l}\text { Post-transplant } \\
\qquad(n=30)\end{array}$} \\
\hline & & $\begin{array}{c}\text { Compensated } \\
(n=79)\end{array}$ & $\begin{array}{l}\text { Decompensated } \\
\qquad(n=7)\end{array}$ & & \\
\hline Age, years, mean \pm SD & $47 \pm 0.72$ & $55 \pm 1.3$ & $54 \pm 5.1$ & $54 \pm 2.2$ & $58 \pm 2.1$ \\
\hline \multicolumn{6}{|l|}{ Ethnicity } \\
\hline East Asian & $196(66)$ & $47(59)$ & $3(43)$ & $12(52)$ & $19(63)$ \\
\hline Southeast Asian & $35(12)$ & $6(8)$ & $1(14)$ & $4(17)$ & $3(10)$ \\
\hline Married or common-law & $201(72)$ & $49(66)$ & $5(83)$ & $14(67)$ & $16(57)$ \\
\hline \multicolumn{6}{|l|}{ Employment } \\
\hline Full-time & $181(66)$ & $42(56)$ & $2(33)$ & $13(62)$ & $5(19)$ \\
\hline \multicolumn{6}{|l|}{ Annual Income, \$ } \\
\hline$<20,000$ & $68(26)$ & $21(30)$ & $1(17)$ & $7(35)$ & $5(20)$ \\
\hline $20,000-40,000$ & $70(27)$ & $16(23)$ & $2(33)$ & $6(30)$ & $6(24)$ \\
\hline \multicolumn{6}{|l|}{ Charlson Index } \\
\hline 0 & $251(86)$ & $61(77)$ & $4(67)$ & $16(73)$ & $14(47)$ \\
\hline 1 & $26(9)$ & $13(17)$ & $0(0)$ & $4(18)$ & $13(43)$ \\
\hline$\geq 2$ & $14(7)$ & $5(5)$ & $2(33)$ & $2(10)$ & $3(10)$ \\
\hline \multicolumn{6}{|l|}{ Language of response } \\
\hline English & $207(70)$ & $53(67)$ & $5(71)$ & $14(63)$ & $22(76)$ \\
\hline Cantonese & $41(14)$ & $16(20)$ & $1(14)$ & $5(23)$ & $6(21)$ \\
\hline Mandarin & $46(16)$ & $10(13)$ & $1(14)$ & $3(14)$ & $1(3)$ \\
\hline \multicolumn{6}{|l|}{ Treatment } \\
\hline No treatment & $179(61)$ & $27(34)$ & $1(14)$ & $4(17)$ & $3(10)$ \\
\hline Lamivudine & $40(14)$ & $26(33)$ & $3(42)$ & $13(57)$ & $20(67)$ \\
\hline
\end{tabular}

Data presented as $n$ (\%) unless otherwise indicated

health states associated with HBV infection. In others, patients were asked to evaluate their own health. Because methods and populations varied, the effect of $\mathrm{CHB}$ on quality of life remains uncertain.

The aim of the present study was to systematically and comprehensively evaluate the HRQOL associated with CHB infection using version 2 of the Short-Form 36 Health Survey (SF36v2), the EQ5D survey, a visual analogue scale (VAS), the Health Utilities Index Mark 3 (HUI3) and standard gamble (SG). We evaluated patients in their preferred language across the spectrum of HBV disease, from mild chronic hepatitis to post-transplantation. We adopted nonpreferencebased and preference-based measurement perspectives, using psychometric instruments, as well as community-weighted and patient-derived utility scores.

\section{METHODS}

Research ethics approval

The present study was approved by the University Health Network Research Ethics Board and the University of Toronto Research Ethics Board (Toronto, Ontario).

Setting

Consecutive patients with HBV-related illness between July 2, 2007, and March 11, 2009, were included. Patients were recruited from liver clinics at the Toronto General Hospital, Toronto Western Hospital,
Princess Margaret Hospital and the liver transplant clinics at the Toronto General Hospital (Toronto, Ontario). These hospitals comprise the University Health Network, a tertiary care referral centre in Toronto, Ontario.

\section{Inclusion criteria}

Outpatients with documented HBV infection, $\geq 16$ years of age and who were fluent in English, Cantonese or Mandarin were included.

HRQoL and measurement instruments

Once written consent was obtained, patients with $\mathrm{CHB}$ attending the clinics were asked to complete non-preference-based instruments (SF36v2) and preference-based instruments (EQ5D, VAS and HUI3) during their visit. The SF36v2 has eight dimensions of health: physical functioning, social functioning, role limitations due to physical problems, role limitations due to emotional problems, mental health, energy/vitality, pain and general health perception. These eight dimensions can be reduced to two summary scores: a physical component score (PCS) and a mental component score (MCS). The EQ5D is a questionnaire that characterizes health in terms of mobility, selfcare, usual activities, pain/discomfort and anxiety/depression on three levels to define HRQoL values (ie, utilities) for 245 health states. The VAS scale used in the EQ5D is a vertical line on a page with a 0 at one end representing worst possible health and a 1 at the other end 
TABLE 2

Non-preference-based quality of life: Short-Form 36 Health Survey (version 2) scores for hepatitis B virus patients at different disease stages compared with United States (US) population norms

\begin{tabular}{|c|c|c|c|c|c|c|c|c|c|c|}
\hline & $\begin{array}{c}\text { Physical } \\
\text { functioning }\end{array}$ & $\begin{array}{c}\text { Role } \\
\text { physical }\end{array}$ & $\begin{array}{l}\text { Bodily } \\
\text { pain }\end{array}$ & $\begin{array}{l}\text { General } \\
\text { health }\end{array}$ & Vitality & $\begin{array}{c}\text { Social } \\
\text { functioning }\end{array}$ & $\begin{array}{c}\text { Role } \\
\text { emotional }\end{array}$ & $\begin{array}{l}\text { Mental } \\
\text { health }\end{array}$ & PCS & MCS \\
\hline $\begin{array}{l}\text { US general } \\
\text { population } \\
(n=4842)^{\star}\end{array}$ & $50.0(0.14)$ & $50.0(0.14)$ & $50.0(0.14)$ & $50.0(0.14)$ & $50.0(0.14)$ & $50.0(0.14)$ & $50.0(0.14)$ & $50.0(0.14)$ & $50(0.14)$ & $50(0.14)$ \\
\hline $\begin{array}{l}\text { Noncirrhotic CHB } \\
\quad(n=294)\end{array}$ & $52.5(0.55)$ & $51.8(0.42)$ & $55.3(0.47)$ & $48.4(0.57)$ & $54.6(0.58)$ & $50.6(0.51)$ & $49.3(0.52)$ & $50.9(0.60)$ & $53.1(0.35)$ & $50.1(0.41)$ \\
\hline $\begin{array}{l}\text { Compensated } \\
\text { cirrhosis }(n=79)\end{array}$ & $48.6(1.2)^{\dagger}$ & $48.6(1.1)^{\dagger}$ & $54.53(1.0)$ & $46.7(1.1)$ & $53.84(1.01)$ & $48.84(1.0)$ & $47.12(1.3)$ & $49.6(1.1)$ & $50.4(0.87)^{\dagger}$ & $49.2(0.92)$ \\
\hline $\begin{array}{c}\text { Decompensated } \\
\text { cirrhosis }(n=7)\end{array}$ & $39.3(5.3)^{\dagger}$ & $33.7(6.4)^{\dagger}$ & $41.2(4.3)^{\dagger}$ & $39.4(5.7)^{\dagger}$ & $40.9(5.1)^{\dagger}$ & $38.9(7.1)^{\dagger}$ & $32.5(8.1)^{\dagger}$ & $41.2(6.6)$ & $39.4(4.3)^{\dagger}$ & $38.5(3.4)^{\dagger}$ \\
\hline $\operatorname{HCC}(n=23)$ & $47.3(2.4)$ & $48.2(2.1)$ & $51.3(2.5)$ & $46.9(2.1)$ & $55.4(1.9)$ & $49.6(2.4)$ & $49.2(2.5)$ & $54.9(2.3)$ & $47.2(2.0)^{\dagger}$ & $53.5(2.0)$ \\
\hline $\begin{array}{l}\text { Post-transplant } \\
(n=30)\end{array}$ & $47.0(2.1)^{\dagger}$ & $47.5(2.2)$ & $50.7(2.2)$ & $47.2(2.0)$ & $53.2(1.9)$ & $47.6(2.1)$ & $47.3(2.1)$ & $51.3(2.1)$ & $47.7(2.0)^{\dagger}$ & $50.6(2.1)$ \\
\hline
\end{tabular}

Data presented as Short-Form 36 Health Survey, version 2 scores (standard error). *Data from reference $20 ;{ }^{\dagger}$ Statistically significant (ie, P<0.05) differences in scores for the disease group compared with the noncirrhotic chronic hepatitis B (CHB) disease group. HCC Hepatocellular carcinoma; MCS Mental component summary; PCS Physical component summary

representing best possible health. The preference score is the measurement of the distance between zero and the mark made by respondent indicating his or her current health state. The HUI3 characterizes health using eight attributes: vision, hearing, speech, ambulation, dexterity, emotion, cognition and pain on five to six levels to define 972,000 health states scored between -0.37 (worst possible health) and 1 (best possible health). The negative values represent health states worse than dead. Validated versions of each of these instruments in English, Cantonese and Mandarin have been developed (12-15). These instruments have also been used to measure HRQoL in patients with CHB infection $(10,11,16-18)$.

Following completion of the surveys, a probability wheel was used as a prop to elicit patients' SG utilities using two practice scenarios and the patient's current health state. Respondents were asked to choose between two options: remain in their current health state without improvement; or take a hypothetical medication that would result in either full health or immediate death. The probability of death in the latter option was changed until the respondent reached a point of indifference between the two options. The utility for current health was calculated as 1 minus the probability of death at the point of indifference.

\section{Baseline patient data}

Participants also completed a questionnaire describing sex, age, ethnicity, education level and income, as well as risk factors for HBV infection. A systematic chart review was also performed to extract the following data: coexisting illness categorized using the Charlson comorbidity index (19), liver enzyme levels, liver biopsy reports, radiology reports and treatment history.

Each patient with $\mathrm{CHB}$ was classified into one of five stages: $\mathrm{CHB}$ in the absence of cirrhosis $(n=294)$; compensated cirrhosis - cirrhosis based on liver biopsy results or cirrhosis reported on ultrasound imaging $(n=79)$; decompensated cirrhosis - cirrhosis with a history of either ascites, variceal bleeding or hepatic encephalopathy as reported in the chart review $(n=7)$; HCC - patients with features of typical HCC demonstrated by a liver biopsy or triphasic computed tomography $(n=23)$; and post-liver transplantation $(n=30)$.

Statistical analysis of patient preferences and utility estimates The means and corresponding 95\% CIs were calculated for each instrument for each health state. ANOVA and Tukey's post hoc test were performed for each instrument to determine whether differences existed across disease stages, among languages of response or from responses given by patients with $\mathrm{CHC}$ in the same clinic population. To compare scores across disease stage groups, age was adjusted using linear regression for each disease stage. The utility scores were the dependent variables and age was the independent variable. Scores were standardized to 50 years of age.

The SF36v2, EQ5D, VAS and HUI3 were compared with population norms using Student's $t$ tests after adjusting the means and SDs to match the age distribution of study patients in the five disease stages. The SF36v2 norms were based on a survey mailed to 4843 United States residents (20). The EQ5D and VAS norms were based on a mailed general population survey of 1555 respondents conducted in Alberta (21). The HUI3 norms were based on a survey of 7946 Canadians with no chronic conditions (22). These scores were compared with scores obtained from a previous study of patients with hepatitis $\mathrm{C}$ who were recruited from the same liver clinics (23).

General linear models for each instrument were constructed to determine which clinical and demographic factors might influence quality of life. Variables significantly related $(\mathrm{P}<0.05)$ to HRQoL scores in univariate analyses were then used in a multivariate general linear model for each quality of life instrument. Statistical analysis was performed using SAS version 9.2 (SAS Institute, USA).

\section{RESULTS}

Among the 486 sequential clinic patients approached, 40 declined to participate and 13 failed to complete the study. Thus, 433 individuals completed the study, yielding an overall participation rate of $89.1 \%$.

Sociodemographic features of patients enrolled in the utility study Table 1 summarizes the sociodemographic and clinical characteristics of the study sample. The mean age of the cohort was 50 years; patients with noncirrhotic hepatitis $B$ were younger than those with compensated cirrhosis, $\mathrm{HCC}$ and post-transplantation $(\mathrm{P}<0.05)$. Patients with noncirrhotic hepatitis $\mathrm{B}$ also had fewer comorbidities compared with patients with decompensated cirrhosis and those post-transplantation. A large proportion of patients were either from east Asia (64\% from mainland China, Hong Kong, Japan, Macau, Mongolia, North Korea, South Korea or Taiwan) or southeast Asia (11\% from Brunei, Burma, Cambodia, East Timor, Indonesia, Laos, Malaysia, Philippines, Singapore, Thailand or Vietnam). Nevertheless, $70 \%$ of the participants completed the study in English. The study sample was predominantly male $(70.5 \%)$, with approximately two-thirds being in a stable relationship (married/common-law/engaged). Nearly one-half $(47 \%)$ reported an annual income of more than $\operatorname{CAD} \$ 40,000$.

\section{SF36v2 HRQoL scores}

The scores elicited using the SF36v2 are presented in Table 2. Among all of the disease groups, patients with noncirrhotic CHB had the highest scores across all attributes. Patients with cirrhosis had lower scores compared with noncirrhotic patients, with the lowest scores 


\begin{tabular}{|c|c|c|c|c|}
\hline & \multicolumn{4}{|c|}{ Utility instrument } \\
\hline & Standard gamble & Health Utilities Index, Mark 3 & Visual analogue scale & EQ5D \\
\hline Canadian population norm & - & $0.93(0.85-1.01)^{\star}$ & $0.81(0.80-0.82)^{\dagger}$ & $0.86(0.85-0.87)^{\dagger}$ \\
\hline Noncirrhotic chronic hepatitis B $(n=294)$ & $0.89(0.87-0.91)$ & $0.87(0.85-0.88)$ & $0.80(0.79-0.82)$ & $0.92(0.91-0.94)$ \\
\hline Decompensated cirrhosis $(n=7)$ & $0.82(0.60-1.00)$ & $0.49(0.22-0.75)^{\ddagger}$ & $0.63(0.29-0.83)^{\ddagger}$ & $0.73(0.39-1.00)^{\ddagger}$ \\
\hline Hepatocellular carcinoma $(n=23)$ & $0.84(0.77-0.92)$ & $0.85(0.76-0.95)$ & $0.77(0.67-0.88)$ & $0.81(0.67-0.94)^{\ddagger}$ \\
\hline Post-transplant $(n=30)$ & $0.86(0.79-0.93)$ & $0.72(0.60-0.83)^{\ddagger}$ & $0.80(0.75-0.87)$ & $0.84(0.77-0.91)$ \\
\hline
\end{tabular}

Data presented as mean ultility $(95 \% \mathrm{Cl}) .{ }^{*}$ Reference $22 ;{ }^{\dagger}$ Reference $21 ;{ }^{\ddagger}$ Statistically significant $(i e, P<0.05)$ differences in scores for the disease group compared with the noncirrhotic chronic hepatitis $B$ disease group

\section{TABLE 4}

Predictors of health-related quality of life from linear regression models

\begin{tabular}{|c|c|c|c|c|c|c|c|c|c|c|c|c|}
\hline \multirow[b]{2}{*}{ Variable } & \multicolumn{2}{|r|}{ PCS } & \multicolumn{2}{|r|}{ MCS } & \multicolumn{2}{|c|}{ Standard gamble } & \multicolumn{2}{|r|}{ HUI3 } & \multicolumn{2}{|r|}{ VAS } & \multicolumn{2}{|r|}{ EQ5D } \\
\hline & $\mathrm{B}^{*}$ & $95 \% \mathrm{Cl}$ & $\mathrm{B}^{*}$ & $95 \% \mathrm{Cl}$ & $\mathrm{B}^{*}$ & $95 \% \mathrm{Cl}$ & $\mathrm{B}^{*}$ & $95 \% \mathrm{Cl}$ & $\mathrm{B}^{*}$ & $95 \% \mathrm{Cl}$ & $\mathrm{B}^{*}$ & $95 \% \mathrm{Cl}$ \\
\hline $\operatorname{Age}^{\dagger}$ & -0.09 & $-0.03,-0.15$ & 0.08 & $0.16,0.00$ & 0.00 & $0.00,0.00$ & 0.00 & $0.00,0.00$ & 0.00 & $0.00,0.00$ & 0.00 & $0.00,0.00$ \\
\hline $\operatorname{Sex}^{\ddagger}$ & -0.84 & $0.76,-2.43$ & -1.99 & $0.22,-4.20$ & 0.04 & $0.03,0.07$ & -0.05 & $-0.01,-0.09$ & 0.00 & $0.03,-0.04$ & -0.01 & $0.02,-0.05$ \\
\hline ALT & -0.01 & $0.00,-0.03$ & -0.01 & $0.01,-0.02$ & 0.00 & $0.00,0.00$ & 0.00 & $0.00,0.00$ & 0.00 & $0.00,0.00$ & 0.00 & $0.00,0.00$ \\
\hline Charlson index & -1.40 & $-0.33,-2.46$ & 0.27 & $1.75,-1.21$ & -0.04 & $-0.02,-0.06$ & -0.04 & $-0.01,-0.06$ & -0.02 & $0.01,-0.04$ & -0.04 & $-0.01,-0.06$ \\
\hline HBeAg status & 0.78 & $2.49,-0.92$ & 0.07 & $2.45,-2.31$ & 0.02 & $0.05,-0.02$ & 0.03 & $0.28,-0.21$ & 0.02 & $0.06,-0.02$ & 0.01 & $0.04,-0.03$ \\
\hline Marital status ${ }^{\S}$ & -1.53 & $0.01,-3.06$ & -2.66 & $-0.55,-4.78$ & 0.00 & $0.04,-0.03$ & -0.05 & $-0.01,-0.09$ & -0.04 & $0.00,-0.07$ & -0.05 & $-0.02,-0.08$ \\
\hline On antiviral treatment ${ }^{\Uparrow}$ & 0.07 & $1.56,-1.41$ & 1.76 & $3.90,-0.37$ & -1.66 & $1.59,-4.92$ & 0.02 & $0.06,-0.02$ & -0.15 & $3.21,-3.51$ & 0.02 & $0.05,-0.01$ \\
\hline Injection drugs & 5.88 & $11.19,0.56$ & 5.24 & $12.67,-2.19$ & 0.17 & $0.28,0.05$ & 0.24 & $0.38,0.11$ & 0.07 & $0.19,-0.05$ & 0.06 & $0.17,-0.05$ \\
\hline Lives with hepB & 0.30 & $1.96,-1.36$ & 0.98 & $3.29,-1.34$ & -0.02 & $0.02,-0.05$ & 0.01 & $0.06,-0.03$ & 0.00 & $0.04,-0.03$ & 0.92 & $0.95,0.89$ \\
\hline Men having sex with men & 2.74 & $6.66,-1.19$ & -5.93 & $-0.47,-11.38$ & 0.02 & $0.11,-0.07$ & 0.00 & $0.10,-0.10$ & -0.04 & $0.04,-0.13$ & 0.02 & $0.10,-0.06$ \\
\hline Sexual partner with hepB & 1.44 & $4.20,-1.32$ & 1.67 & $5.53,-2.19$ & 0.04 & $0.10,-0.02$ & 0.04 & $0.12,-0.03$ & 0.05 & $0.11,-0.01$ & 0.24 & $0.29,0.18$ \\
\hline In prison & 0.83 & $6.17,-4.50$ & 0.65 & $8.09,-6.79$ & 0.02 & $0.14,-0.09$ & -0.09 & $0.04,-0.23$ & 0.14 & $0.25,0.02$ & -0.02 & $0.08,-0.13$ \\
\hline Tattoo & -2.23 & $-4.60,0.14$ & 0.56 & $5.59,-4.47$ & 0.01 & $0.08,-0.07$ & 0.04 & $0.13,-0.05$ & 0.05 & $0.13,-0.02$ & 0.01 & $0.09,-0.06$ \\
\hline Body piercing & 0.57 & $2.77,-1.64$ & 2.00 & $5.06,-1.06$ & -0.01 & $0.04,-0.05$ & 0.03 & $0.09,-0.02$ & 0.01 & $0.06,-0.03$ & 0.02 & $0.07,-0.02$ \\
\hline Hemophilia & 3.40 & $14.01,-7.22$ & -3.91 & $10.91,-18.72$ & 0.11 & $0.33,-0.12$ & 0.08 & $0.35,-0.20$ & -0.12 & $0.11,-0.35$ & 0.20 & $0.41,-0.02$ \\
\hline
\end{tabular}

*Unstandardized Beta coefficient. ${ }^{\dagger}$ Age was calculated using the birth date and date of study completion; ${ }^{\ddagger}$ Sex was coded as $1=$ male, $2=$ female; ${ }^{\S}$ Marital status is a binary variable with, 1 = married, common-law or engaged and 2 = not married, common-law or engaged; ${ }^{\top}$ On antiviral treatment is a binary variable with, 1 = no treatment and 2 = on an oral antiviral treatment. ALT Alanine aminotransferase; HBeAg Hepatitis B e antigen; hepB Hepatitis B; HUI3 Health Utilities Index Mark 3; Lives with hepB Respondent lives in a household that includes an individual infected with hepatitis B; MCS Mental component summary; PCS Physical component summary; VAS Visual analogue scale. Bolded values indicate statistical significance

\section{TABLE 5}

Comparison of patient-elicited Short-Form 36 Health Survey, version 2 (SF36v2) mean physical component score (PCS) and mean mental component score (MCS) with published studies in hepatitis B virus-specific populations

\begin{tabular}{|c|c|c|c|c|c|c|c|c|}
\hline & & & \multicolumn{6}{|c|}{ Published SF36v2 summary scores, author (reference), year } \\
\hline & \multicolumn{2}{|c|}{ Current study } & \multicolumn{2}{|c|}{ Ong et al $(9)^{\star}, 2008(n=432)$} & \multicolumn{2}{|c|}{ Tan et al (28), $2008(n=108)$} & \multicolumn{2}{|c|}{ Bondini et al $(10)^{\dagger}, 2007(n=146)$} \\
\hline & PCS (median) & MCS (median) & PCS & MCS & PCS & MCS & PCS & MCS \\
\hline Noncirrhotic CHB & $53.09(54.38)$ & $50.08(52.81)$ & 56.34 & 44.81 & 50.7 & 48.5 & 51.5 & 50.2 \\
\hline Compensated cirrhosis & $50.43(53.18)$ & $49.18(53.03)$ & 55.44 & 48.48 & & & & \\
\hline Decompensated cirrhosis & $39.46(37.72)$ & $38.51(34.23)$ & 46.53 & 43.03 & & & & \\
\hline Hepatocellular carcinoma & $47.17(48.42)$ & $53.91(56.21)$ & 45.27 & 43.1 & & & & \\
\hline Post-transplant & $47.73(52.41)$ & $50.57(50.96)$ & 46.74 & 44.33 & & & & \\
\hline
\end{tabular}

${ }^{*}$ Reported median scores; ${ }^{\dagger}$ Scores reflect patients from all disease states and not only noncirrhotic patients. CHB Chronic hepatitis $B$

observed in patients with decompensated cirrhosis for all attributes. The scores for the different attributes for patients with HCC were higher than noncirrhotic patients for some while lower for others. For individuals who underwent liver transplantation, scores were higher than patients with decompensated cirrhosis while similar to patients with HCC.

Patients without cirrhosis had scores similar to the general population. Of interest was that physical functioning, role physical, bodily pain and vitality attributes, which comprise the PCS score, were all higher among patients with noncirrhotic CHB compared with general population norms.
HRQoL utility estimates

Utility scores are reported in Table 3. The results of the utility scoring instruments were quantitatively similar to that of the SF36v2. Noncirrhotic patients had the highest scores, which were similar to the general population. Patients with cirrhosis had a consistent trend toward decreasing utility as liver disease stage severity increased from noncirrhotic CHB to compensated cirrhosis and then to decompensated cirrhosis. As was determined by the SF36v2, patients with HCC had lower utility scores compared with noncirrhotic patients; however, they were not as low as patients with decompensated cirrhosis. Patients who underwent a liver transplant had higher utility scores compared 


\begin{tabular}{|c|c|c|c|c|c|c|c|c|c|c|}
\hline & & & & & \multicolumn{6}{|c|}{ Published utility values, author (reference), year } \\
\hline & \multicolumn{4}{|c|}{$\begin{array}{l}\text { Patient-elicited mean scores } \\
\text { from current study }\end{array}$} & \multirow{2}{*}{$\begin{array}{c}\begin{array}{c}\text { Levy et al } \\
(18), 2008 \\
(n=534)\end{array} \\
\text { SG }\end{array}$} & \multirow{2}{*}{$\begin{array}{c}\text { Dan et al } \\
\begin{array}{c}(11)^{*}, 2008 \\
(n=140)\end{array} \\
\text { HUI2 }\end{array}$} & \multirow{2}{*}{$\begin{array}{c}\begin{array}{c}\text { Bondini et al } \\
(10)^{*}, 2007 \\
(n=146)\end{array} \\
\text { HUI2 }\end{array}$} & \multicolumn{2}{|c|}{$\begin{array}{l}\text { Ong et al }(9)^{\dagger}, 2007 \\
\qquad(n=432)\end{array}$} & \multirow{2}{*}{$\begin{array}{c}\begin{array}{c}\text { Dan et al }(11)^{*} \\
2008(n=140)\end{array} \\
\text { SF6D }\end{array}$} \\
\hline & SG & HUI3 & EQ5D (median & VAS (median) & & & & EQ5D & VAS & \\
\hline Noncirrhotic CHB & 0.89 & 0.87 & $0.92(1)$ & $0.80(0.80)$ & 0.68 & 0.87 & 0.78 & 1.0 & 0.82 & 0.78 \\
\hline Compensated cirrhosis & 0.87 & 0.81 & $0.88(1)$ & $0.78(0.80)$ & 0.69 & & & 1.0 & 0.79 & \\
\hline Decompensated cirrhosis & 0.82 & 0.49 & $0.73(0.85)$ & $0.63(0.65)$ & 0.35 & & & 0.85 & 0.70 & \\
\hline Hepatocellular carcinoma & 0.84 & 0.85 & $0.81(1)$ & $0.77(0.85)$ & 0.38 & & & 0.83 & 0.70 & \\
\hline Post-transplant & 0.86 & 0.72 & $0.84(0.85)$ & $0.80(0.85)$ & 0.67 & & & 0.85 & 0.80 & \\
\hline
\end{tabular}

*Scores derived from patients from all disease states and not only noncirrhotic patients; ${ }^{\dagger}$ Scores are reported as median values only. CHB Chronic hepatitis B; HUI2 Health utilities index mark 2; HUI3 Health utilities index mark 3; SF6D Short-Form Health Survey 6D; SG Standard gamble; VAS Visual analogue scale

with patients with decompensated cirrhosis and HCC; however, they were not comparable with noncirrhotic patients as was found by the SF36v2. As was observed in the physical attributes of the SF36v2, the EQ5D scores of noncirrhotic patients were higher compared with the general population.

\section{Predictors of utility and HRQoL}

General linear models were created to identify the set of variables that best predicted HRQoL in patients chronically infected with HBV $(\mathrm{P}<0.05)$. The adjusted $\mathrm{R}^{2}$ values were low and ranged between 0.048 and 0.251 . Three factors consistently predicted utility scores: age, number of comorbidities and marital status (Table 4). A one-year increase in age was associated with lower HRQoL as measured across all instruments except the MCS score of the SF36v2. As expected, patients with a greater number of comorbidities, as measured by the Charlson Index, had lower HRQoL scores. Interestingly, patients who reported themselves to be in a relationship (married/engaged/commonlaw) had higher scores compared with patients who were not.

Risk factors for HBV infection were not consistently associated with a difference in utility. Alanine aminotransferase levels showed no consistent correlation to HRQoL across instruments. In the present study, there were too few patients who had undergone a liver biopsy to assess the association with HRQoL scores. With respect to the effect of antiviral therapy on quality of life, there was no statistically significant difference in adjusted scores between patients on and off treatment, regardless of disease severity $(\mathrm{P}>0.05)$.

\section{Comparison of measurement tools}

The difference in utility estimates for each disease stage varied similarly for each instrument: patients with noncirrhotic hepatitis B had the highest scores and as the stage of liver damage severity increased, the utilities decreased as measured by the EQ5D, VAS and SG. However, the scores obtained from the HUI3 differed from those derived using other instruments because the HUI3 scores were higher for patients with HCC compared with those post-transplant (Figure 1). As expected, VAS scores were lower than EQ5D, SG and HUI3 scores by 0.106 , 0.086 and 0.043 , respectively $(P<0.0001)$. Scores obtained from the EQ5D and SG were higher than those elicited using the HUI3 by 0.061 and 0.038 , respectively $(\mathrm{P}<0.0006)$. There was no significant difference between the EQ5D and SG scores.

\section{Comparisons of $\mathrm{CHB}$ and $\mathrm{CHC}$ sample populations}

The data in the present study were compared with the data obtained in a similar study performed in hepatitis C-infected patients attending the same liver clinics at the University Health Network (23). There was a similar trend observed with regard to the relative scores between disease states: patients in a noncirrhotic chronic state had the highest scores and patients with more progressive liver disease had the lower scores. Overall, hepatitis $\mathrm{C}$-infected patients had lower utility scores than HBV-infected patients as measured by every utility instrument $(\mathrm{P}<0.05)$. In addition, both PCS and MCS scores from the SF36v2 for $\mathrm{CHC}$ patients were lower than those in the present study population $(\mathrm{P}<0.05)$.

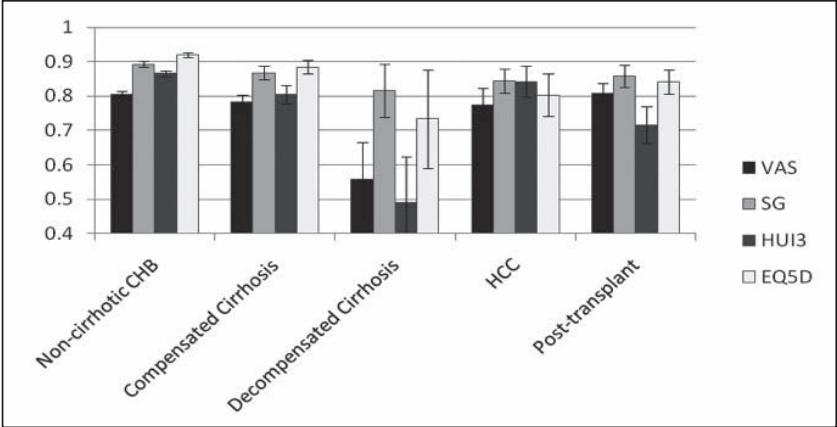

Figure 1) Mean utilities and health-related quality of life scores stratified according to disease stage of patients with chronic hepatitis B (CHB). HCC Hepatocellular carcinoma; HUI3 Health Utilities Index Mark 3; SG Standard gamble; VAS Visual analogue scale

\section{DISCUSSION}

In HBV-infected patients, HRQoL was only impaired among those who developed late-stage liver disease. The aim of our study was to determine the HRQoL of patients with CHB using the SF36v2, EQ5D, VAS, HUI3 and SG instruments. We found that lower HRQoL scores did not appear to be associated with HBV infection itself, but rather with the presence of cirrhosis and HCC (Figure 1). We also found that older age, number of comorbidities and not being in a longterm relationship were associated with lower HRQoL.

Other studies have found similar results. For example, Ong et al (9) stratified 432 patients into respective disease stages and assessed their HRQoL using the SF36v2, the EQ5D and the VAS. They also found no difference in HRQoL between noncirrhotic HBV patients and uninfected individuals. Impairment of HRQoL was only observed in those with cirrhosis or liver failure.

In a multinational study by Levy et al (18), the HRQoL for disease states related to HBV were elicited using the SG and found to be lower than the values obtained in our study. The differences observed in the results are likely attributable to the different method that was used to obtain the utilities. In our study, patients were asked to evaluate their own health state while in the study by Levy et al (18), patients and noninfected members of the general population were asked to evaluate descriptions of health states related to HBV infection. It is not surprising that lower utilities were found by Levy et al because individuals often provide lower utility scores of descriptions of health states compared with patients who are currently experiencing the disease state (24).

Antiviral treatment does not affect HRQoL

We observed that patients with late-stage disease were more often receiving oral antiviral treatment than patients with early stage disease (Table 1). Lamivudine was the most widely used oral antiviral while only a small proportion of patients were on newer, more potent treatments such as entecavir or tenofovir. None of our patients were being 
treated with interferon. Overall, we found no difference in HRQoL among patients who were receiving and not receiving oral antiviral treatment regardless of stage of disease or measurement instrument. Daily oral antiviral treatment was not associated with lower or higher HRQoL as measured by both preference- and non-preference-based instruments. However, our study did not follow patients prospectively or investigate patients who may have started treatment but failed to continue due to adverse events. Thus, although our study does not suggest that treatment impairs quality of life, we cannot definitively rule out a small aggregate effect.

Significant differences between $\mathrm{HBV}$-infected patients and patients infected with hepatitis $C$ virus

HBV patients without late-stage liver disease do not appear to experience the same impairment in HRQoL seen among patients with hepatitis $\mathrm{C}$ virus (HCV) infection. A study with a design similar to the present study was performed in 2000 on patients with hepatitis C attending the same liver clinics in downtown Toronto (23). Chong et al (23) suggested that HRQOL was significantly diminished in patients with HCV in patients with and without cirrhosis. Chong et al's HCV patients had lower HRQoL scores compared with our patients with HBV $(\mathrm{P}<0.05)$. The patient groups in the Chong et al (23) study differed from ours in that they had higher rates of previous injection drug use, previous incarceration and homosexual activity, and differences in ethnicity and age, which may have resulted in the differences in HRQoL observed compared with our study.

Before 2008, all cost-effectiveness studies assessing treatment options for $\mathrm{CHB}$ used utilities from studies of patients with HCV because data were not available for patients with $\operatorname{HBV}(7,8,25,26)$. These studies assumed that patients with CHB had the same HRQoL as patients with HCV infection. A study by Kanwal et al (7) assessing the cost effectiveness of treatments for HBV used a range of utility estimates for patients with HCV as estimates for HRQoL of patients with HBV that was lower than those elicited from the current study of patients with HBV. Using utilities from patients with $\mathrm{HCV}$ in decision models is potentially problematic. Utility estimates that are biased downward will result in overestimates of the burden of disease from HBV and will make treatment of hepatitis B appear to be more cost effective.

\section{Study limitations}

Our study had several limitations. First, we recruited subjects from tertiary care centres of patients returning for follow-up visits related to CHB. This sample may not represent the entire HBV population because individuals in tertiary care clinics are typically those who have more severe liver disease and/or symptoms. However, because noncirrhotic patients showed no difference in HRQoL compared with the general population, it is unlikely that those not seeking care for hepatitis B would have HRQoL any different from the group of noncirrhotic patients. Nevertheless, studies of patients with hepatitis B in the community may provide a more comprehensive reflection of the effects of hepatitis B on HRQoL. Another major limitation of our study was the number of patients with advanced liver disease. We indentified few patients with decompensated cirrhosis. This is likely attributable to improved management with modern antiviral therapy (27). Finally, the design was cross-sectional, which limited our ability to determine the causal relationships between health state and quality of life.

\section{CONCLUSION}

The aim of the present study was to provide a comprehensive catalogue of HBV-related utilities using the most common measurement tools. Our study findings provide further support to long-term therapy using oral antivirals to prevent the progression of liver disease and HCC associated with HBV infection because therapy does not appear to significantly affect the HRQoL of patients receiving treatment. In the future, longitudinal studies could comprehensively investigate the effects of viral resistance on HRQoL as well as differences in HRQoL that may exist for patients on different antiviral treatments.
FINANCIAL DISCLOSURE: This study was supported by an unrestricted project grant from Gilead Sciences. The design and conduct of the study, collection, management, analysis, and interpretation of the data and preparation of the manuscript were conducted and controlled independently from the sponsor.

ROLE OF THE SPONSORS: None of the funding organizations or sponsors had any role in the design and conduct of the study; the collection, management, analysis, or interpretation of the data; or the preparation, or approval of the manuscript.

AUTHOR CONTRIBUTIONS: Dr Krahn had full access to all of the data in the study and takes full responsibility for the integrity of the data and the accuracy of the data analysis. Study concept and design: Woo and Krahn. Data acquisition: Woo, Sherman, Heathcote, Yim, Wong, Therapodos and Lilly. Analysis and interpretation of data: Woo, Tomlinson, Sherman, Heathcote and Krahn. Drafting of the manuscript: Woo, Heathcote, Sherman and Wong. Critical revision of manuscript for important intellectual content: Woo, Tomlinson, Sherman, Wong, Ungar, Einarson, Heathcote and Krahn. Statistical analysis: Woo and Tomlinson. Administrative, technical, or material support: Woo. Study supervision: Ungar, Einarson, Sherman, Heathcote and Krahn.

\section{REFERENCES}

1. Custer B, Sullivan SD, Hazlet TK, et al. Global epidemiology of hepatitis B virus. J Clin Gastroenterol 2004;38(10 Suppl 3):S158-68.

2. Leber A, Sherman M, Estimation of immigration related chronic hepatitis B infection and hepatocellular carcinoma development in Canada from 1981-2006 (S022). Canadian Digestive Diseases Week, February 27 to March 2, 2009, Banff, Alberta.

3. Kim WR. Epidemiology of hepatitis B in the United States. Hepatology 2009;49(5 Suppl):S28-34.

4. Weinbaum CM, Mast EE, Ward JW. Recommendations for identification and public health management of persons with chronic hepatitis B virus infection. Hepatology 2009;49(5 Suppl):S35-44.

5. Lavanchy D. Worldwide epidemiology of HBV infection, disease burden, and vaccine prevention. J Clin Virol 2005;34(Suppl 1):S1-3.

6. Wang WL, Wang CJ, Tseng HF. Comparing knowledge, health beliefs, and self-efficacy toward hepatitis B prevention among university students with different hepatitis B virus infectious statuses. J Nurs Res 2009;17:10-9.

7. Kanwal F, Farid M, Martin P, et al. Treatment alternatives for hepatitis B cirrhosis: A cost-effectiveness analysis.

Am J Gastroenterol 2006;101:2076-89.

8. Takeda A, Jones J, Shepherd J, et al. A systematic review and economic evaluation of adefovir dipivoxil and pegylated interferon-alpha-2a for the treatment of chronic hepatitis B. J Viral Hepat 2007;14:75-88.

9. Ong SC, Mak B, Aung MO, et al. Health-related quality of life in chronic hepatitis B patients. Hepatology 2008;47:1108-17.

10. Bondini S, Kallman J, Dan A, et al. Health-related quality of life in patients with chronic hepatitis B. Liver Int 2007;27:1119-25.

11. Dan AA, Kallman JB, Srivastava R, et al. Impact of chronic liver disease and cirrhosis on health utilities using SF-6D and the health utility index. Liver Transpl 2008;14:321-6.

12. Horsman J, Furlong W, Feeny D, et al. The Health Utilities Index (HUI): Concepts, measurement properties and applications. Health Qual Life Outcomes 2003;1:54.

13. Luo N, Chew LH, Fong KY, et al. Do English and Chinese EQ-5D versions demonstrate measurement equivalence? An exploratory study. Health Qual Life Outcomes 2003;1:7.

14. Luo N, Chew LH, Fong KY, et al. Validity and reliability of the EQ-5D self-report questionnaire in English-speaking Asian patients with rheumatic diseases in Singapore. Qual Life Res 2003;12:87-92.

15. Li L, Wang HM, Shen Y. Chinese SF-36 Health Survey: Translation, cultural adaptation, validation, and normalisation. J Epidemiol Community Health 2003;57:259-63.

16. Lam ET, Lam CL, Lai CL, et al. Psychometrics of the chronic liver disease questionnaire for Southern Chinese patients with chronic hepatitis B virus infection. World J Gastroenterol 2009;15:3288-97. 
17. Orito E, Ichida T, Sakugawa $H$, et al. Geographic distribution of hepatitis $B$ virus (HBV) genotype in patients with chronic HBV infection in Japan. Hepatology 2001;34:590-4.

18. Levy AR, Kowdley KV, Iloeje U, et al. The impact of chronic hepatitis B on quality of life: A multinational study of utilities from infected and uninfected persons. Value Health 2008;11:527-38.

19. Charlson ME, P. Pompei P, Ales KL, et al. A new method of classifying prognostic comorbidity in longitudinal studies: Development and validation. J Chronic Dis 1987;40:373-83.

20. Ware JE, Kosinski M, Dewey JE, How to score version two of the SF-36 Health Survey. Lincoln: Quality Metric, 2009.

21. Johnson JA, Pickard AS, Comparison of the EQ-5D and SF-12 health surveys in a general population survey in Alberta, Canada. Med Care 2000;38:115-21.

22. Mittmann N, Trakas K, Risebrough N, et al. Utility scores for chronic conditions in a community-dwelling population. Pharmacoeconomics 1999;15:369-76.
23. Chong CA, Gulamhussein A, Heathcote EJ, et al. Health-state utilities and quality of life in hepatitis $\mathrm{C}$ patients. Am J Gastroenterol 2003;98:630-8.

24. Menzel P, Dolan P, Richardson J, et al. The role of adaptation to disability and disease in health state valuation: A preliminary normative analysis. Soc Sci Med 2002;55:2149-58.

25. Sullivan SD, Veenstra DL, Chen PJ, et al. Cost-effectiveness of peginterferon alpha-2a compared to lamivudine treatment in patients with hepatitis B e antigen positive chronic hepatitis B in Taiwan. J Gastroenterol Hepatol 2007;22:1494-9.

26. Veenstra DL, Sullivan SD, Lai MY, et al. HBeAg-negative chronic hepatitis B: Cost-effectiveness of peginterferon alfa-2a compared to lamivudine in Taiwan. Value Health 2008;11:131-8.

27. Liaw YF, Sung JJ, Chow WC, et al. Lamivudine for patients with chronic hepatitis B and advanced liver disease. N Engl J Med 2004;351:1521-31. 


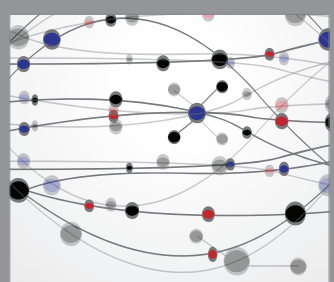

The Scientific World Journal
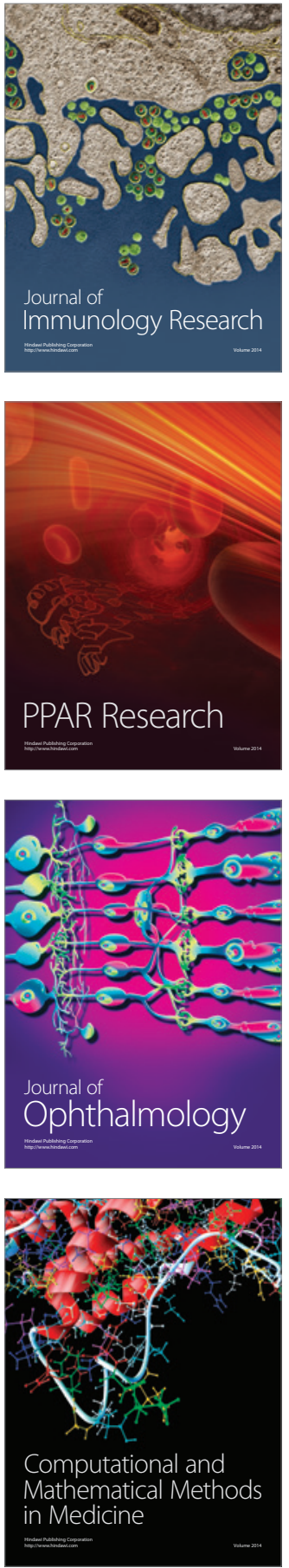

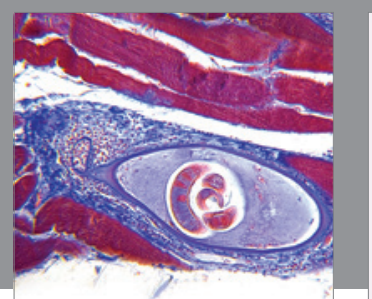

Gastroenterology Research and Practice



\section{Hindawi}

Submit your manuscripts at

http://www.hindawi.com
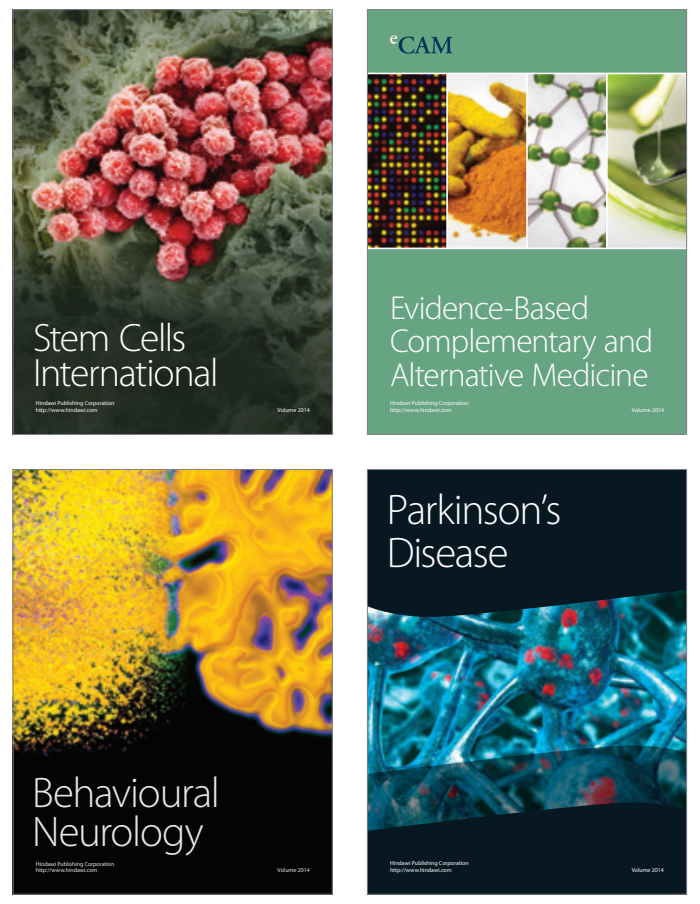
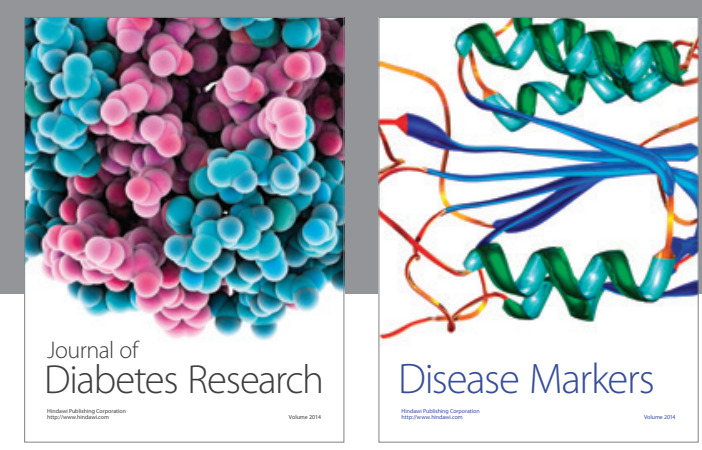

Disease Markers
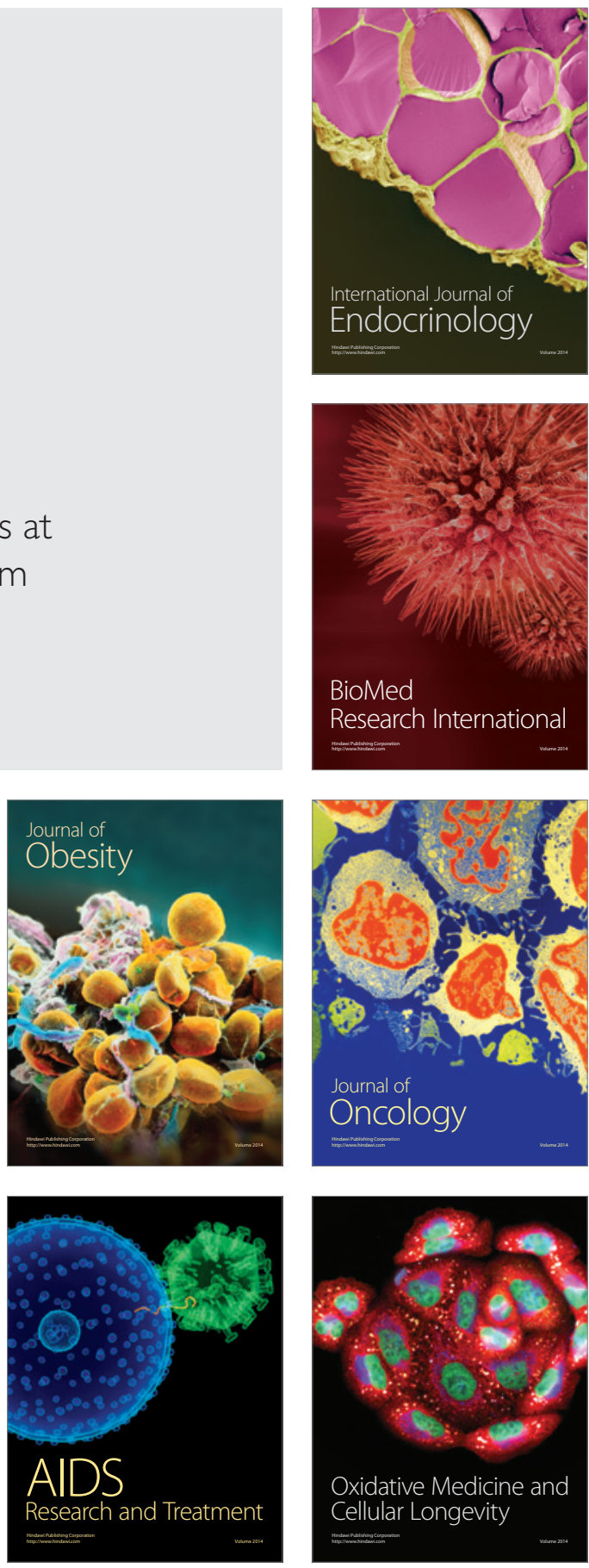